\title{
Intraoperative Rocuronium Reversion by Low Doses of Sugammadex, in Thyroid Surgery, with Monitoring of the Recurrent Laryngeal Nerves
}

\section{${ }^{1 *}$ Margarita Kontoudi, ${ }^{2}$ Maria Gouliami, ${ }^{3}$ Chryso Loizou, ${ }^{4}$ Karmen Kristoloveanou, ${ }^{5}$ Ageliki Pandazi}

${ }^{1} \mathrm{MD}$, Director of Anesthesiology Department, 23 A Kalavryton str., Vrilissia, Athens, 114 Vasilissis Sofias.str, Athens, Greece, ZC 115 27, General Hospital of Athens Hippocratio, Greece

${ }^{2}$ MD, Coordinator Director of Anesthesiology Department, 340 Patission str, Patissia, Athens, General Hospital of Athens Hippocratio, Greece

${ }^{3} \mathrm{MD}$, Director of Anesthesiology Department, 18 Socratous str., Melissia, Athens, General Hospital of Athens Hippocratio, Greece

${ }^{4} \mathrm{MD}$, Director of Anesthesiology Department, 27 Hatzikostanti str., Ampelokipi, Athens, General Hospital of Athens Hippocratio, Greece

${ }^{5}$ Assistant Professor of Anesthesiology, 35 Bouboulinas str., Kalithea, Athens, University of Athens, $2^{\text {nd }}$ Department of Anaesthesiology, Attikon Hospital, Greece

I'markontoudi@yahoo.gr, ${ }^{2}$ maria_gouliami@yahoo.gr, ${ }^{3}$ chrysoloi@yahoo.gr, ${ }^{4}$ car.cristoloveanu@yahoo.gr, ${ }^{5}$ angpant@med.uoa.gr

\begin{abstract}
:
Objectives: In thyroid surgery, where intraoperative monitoring (IONM) of the recurrent laryngeal nerves is used, for induction in anesthesia, we usually use succinylcholine or totally avoid neuromuscular blocking agents. The aim of this study was to investigate if a full dose of rocuronium, reversed by low dose sugammadex, permits to replace the referred methods which are not totally acceptable.

Methods: 75 patients were equally divided in groups $A, B, C$. A received rocuronium, $B$ succinylcholine, $C$ didn't receive any muscle relaxant for induction. We compared intubation conditions among them. In groups $A$ and $B$, we estimated the time after administration of muscle relaxation, that patients were free from muscular blockade, so that IONM could be safely used.

Results: The proportion of good/excellent Intubation Condition Score was significantly greater in groups A and $B$, compared to $C$. No significant difference was found in correspondence portion, between $A$ and $B(p>0,05)$. In $A$, the time for neuromuscular junction recovery was 16, $9 \pm 4,8$ min. Conclusions : Rocuronium 0,6 mg/kg, administered with remifentanil $1 \mathrm{mcg} / \mathrm{kg}$ and propofol $2,5 \mathrm{mg} / \mathrm{kg}$, generally provides excellent or good intubation conditions. Sugammadex makes rocuronium suitable muscle relaxant for thyroid surgery, even when IONM is used.
\end{abstract}

Keywords: Intraoperative Neuromonitoring, Rocuronium, Sugammadex, Thyroid Surgery, Intubation Condition Score

Abbreviations: RLNs : Recurrent Laryngeal Nerves ;IONM : Intraoperative Neuromonitoring ; EMG : Electromyography ; NMBAs : Neuromuscular Blocking Agents ; ICS : Intubation Condition Score ; IDS : Intubation Difficulty Scale ; ECG : Electrocardiogram ; HR : Heart Rate ; NIBP : Non-Invasive Blood Pressure ; SAP : Systolic Arterial Pressure ; DAP : Diastolic Arterial Pressure ; MAP : Mean Arterial Pressure ; SpO2 : Pulse Oximetry ; ETCO2 : End-Expiratory Carbon Dioxide Pressure ; BIS : Bispectral Index ; TOF : Train of four ; NIM : Nerve Integrity Monitor ; NMB : Neuromuscular Blockade ; PTC : Post Tetanic Count : SD : Standard Deviation; ANOVA : Analysis Of Variance.

\section{INTRODUCTION}

Recurrent Laryngeal Nerves' (RLNs) palsy represents one of the most serious complications (besides hypocalcaemia and hematoma), and one of the most frequent causes of medico legal litigation, after thyroid surgery.

Anatomic and functional reservation of the recurrent laryngeal nerves (RLNs) is the gold standard in thyroid surgery. Intraoperative identification of the RLNs is associated with a lower incidence of 
RLNs injury, in terms of transient paralysis (3\%) and permanent paralysis (1\%), compared to no identification of the nerves (transient paralysis of 8-9\% and permanent of 5\%) according to different series. $^{1}$

Intraoperative Neuromonitoring (IONM) of RLNs was proposed to verify the functional integrity of RLNs during thyroid surgery.

IONM is useful to identify the recurrent laryngeal nerves. This technique is safe and reliable in excluding postoperative recurrent laryngeal nerves palsy; it has high accuracy, specificity, sensitivity and negative predictive value. Its application is particularly recommended for high-risk thyroidectomies (reoperations, thyroid cancer). ${ }^{2,3,4}$

Furthermore, IONM has some advantages over visual identification alone. Most injured nerves appear intact by visual inspection only, so IONM provides a more accurate prediction of postoperative neural function. In addition, IONM helps avoid bilateral RLN injury, by postponing the operation of the second side of the thyroid gland, if a nerve injury is considered as probable, in the initial side of a bilateral operation. ${ }^{2}$

Many different nerve monitoring formats have been used. For a variety of reasons including safety, utility and simplicity, systems based on endotracheal tube incorporated electrodes have been proliferated and represent the most popular monitoring equipment format to date. This design allows evoked surface EMG monitoring of left and right thyroarytenoid muscles, during stimulation of RLNs, in monitored thyroid surgery.

The tube is connected with an Electromyographic (EMG) monitor (Medronic, NIM - Response 3.0 System). By using IONM, recurrent laryngeal nerves are located and identified at the tracheoesophageal groove, obtaining an EMG signal, by the application of a sterile, single use, pulsegenerated monopolar stimulator probe (Medtronic Xomed).

The nerves are initially searched for at $2 \mathrm{~mA}$ and fully mapped out. They are then dissected and visually confirmed. Once the nerves are visualized, the stimulation current is turned down to $0.5-0.8$ mA. Normal or pathological EMG responses are continuously recorded. ${ }^{6}$

Neuromuscular Blocking Agents (NMBAs), play a vital role in modern anesthesia practice. Their most important role is to facilitate tracheal intubation. Selection of a NMBA is important in the setting of IONM, during thyroid surgery. An ideal NMBA for this specific operation provides a sufficient degree of muscle relaxation for tracheal intubation and a fast recovery profile, with minimal influence on IONM. Thus: a) the use of succinylcholine, b) the use of small doses of a short acting nondepolarizing NMBA or even, c) the avoidance of use of a NMBA are recommended, for induction in anesthesia in this short of cases. 6,7

Succinylcholine is associated with a variety of adverse effects, from minor to catastrophic and the addition of a full dose of a muscle relaxant agent to the induction in anesthesia regimen, improves the quality of tracheal intubation and contributes to less tracheal morbidity (decreased postoperative hoarseness and vocal cord sequelae). ${ }^{8,9}$

Prolonged paralysis following administration of succinylcholine, given for induction, can happen to patients who have quantitative pseudocholinesterase deficiency, which can be easily identified preoperatively. The problem is much more serious to individuals having qualitative pseudocholinesterase deficiency and are heterozygous or mutant homozygous to atypical pseudocholinesterase. To identify susceptible individuals, the dibucaine number can be determined, but, routine measurement of dibucaine number is currently not standard practice prior to surgery in many institutions.

A new approach to fast recovery from the non depolarizing neuromuscular blockade is to blockade with rocuronium and then reverse with sugammadex, a new pharmaceutical agent that permits fast reversal of steroidal non depolarizing muscle relaxants like rocuronium.

The appropriate time for a suitable dose of sugammadex application depends on the time or the neuromuscular blockade depth as this is accurately determined by accelomyography (TOF - Watch SX). ${ }^{10,11}$

The main objective of this study was to compare three different ways of induction in anesthesia, for the particularly designed thyroid surgery. The first group (A) received a full dose of a non 
depolarizing NMBA (rocuronium) which was reversed soon by low dose of sugammadex, the second group (B) received a depolarizing NMBA (succinylcholine) and the control group (C) didn't receive any muscle relaxant agent. We evaluated: 1) the tracheal intubation conditions, using the tracheal Intubation Condition Score (ICS), 2) the tracheal intubation difficulty, using the tracheal Intubation Difficulty Scale score (IDS), 3) the time after induction in anesthesia that safe control of RLNs using IONM was possible, 4) the quality of surgical anesthesia, 5) the hemodynamic fluctuations and 6) the adverse effects of each induction regimen. ${ }^{12}$

The aim of the study was to investigate if a full dose of rocuronium for induction in anesthesia, reversed as soon as possible by low dose of sugammadex, could replace the other two methods of induction in anesthesia for this short of cases.

\section{MATERIALS AND METHODS}

After obtaining approval from the Ethic Committee and written informed consent, we studied 75 ASA physical status I-II patients, aged between 19 and 76 years, of both sexes, scheduled for elective thyroid surgery with Intraoperative Neuromonitoring (IONM) of the Recurrent Laryngeal Nerves (RLNs). The patients were divided into three equal groups (A, B, C). Groups A and B received muscle relaxant agents (rocuronium and succinylcholine respectively). Group C didn't receive any muscle relaxant agent. Patients with neuromuscular disease or the ones who were receiving medications known to interact with the neuromuscular junction, as well as patients with known difficult intubation, were excluded from the study. We also excluded from the second group, patients who had never received anesthesia before and those who had a personal or family history of delayed recovery from anesthesia, in order to protect them, in a degree, from possible serious complications of succinylcholine.

All patients were premedicated per os: the previous night with $1,5 \mathrm{mg}$ bromazepam and $40 \mathrm{mg}$ pantoprazole and two hours before the operation, with 1, $5 \mathrm{mg}$ bromazepam.

Peripheral venous access was obtained, in every patient, with an intravenous catheter $18 \mathrm{G}$, just after arrival in the operating room.

All patients were connected to a Mennen Medical LTD, model ENVOY monitor for continuous monitoring of:

1) Electrocardiogram (ECG) - Heart Rate (HR)

2) Non-Invasive Blood Pressure (NIBP), Systolic Arterial Pressure (SAP), Diastolic Arterial Pressure (DAP), Mean Arterial Pressure (MAP)

3) Pulse Oximetry $(\mathrm{SpO} 2)$

4) End-Expiratory Carbon Dioxide Pressure (ETCO2)

5) Central Body and Skin Temperature (maintained at $>=35^{\circ} \mathrm{C}$ and $>=32^{\circ} \mathrm{C}$, respectively) In addition, were also monitored:

6) Bispectral Index (BIS) and

7) Neuromuscular Junction activity by Accelomyography, using TOF-Watch SX.

Accelomyography was taking place by stimulating the ulnar nerve through electrodes placed over the ulnar nerve, on the volar side of the wrist and acceleration measurements at the adductor pollicis.

For the estimation of the depth of the neuromuscular blockade created by the non depolarizing neuromuscular blocking agent rocuronium (group A), we used train of four (TOF). ${ }^{13}$

Control twitch height was set to $100 \%$, T0.

The ratio of evoked twitch height (after the depolarizing blocking agent was given) divided by the control twitch height, (\%TW,T1/T0), gives an indication of the depth of depolarizing neuromuscular blockade, provided by succinylcholine.

All patients were premedicated with midazolam $0,02-0,03 \mathrm{mg} / \mathrm{kg}$ i.v., approximately $5 \mathrm{~min}$ before the induction in anesthesia. They were also given $8 \mathrm{mg}$ of dexamethazone and antiemetics $(0,6 \mathrm{mg}$ of droperidol and $8 \mathrm{mg}$ of ondansetron). 


\section{Margarita Kontoudi et al.}

For induction in anesthesia: a) patients of groups $\mathrm{A}$ and $\mathrm{B}$, who received muscle relaxants, were given $1 \mathrm{mcg} / \mathrm{kg}$ of remifentanil, administered over $30 \mathrm{sec}$, simultaneously with propofol $2,5 \mathrm{mg} / \mathrm{kg}$, administered over $45 \mathrm{sec}, \mathrm{b}$ ) patients of group C, who didn't receive any muscle relaxants (control group), were infused remifentanil $1-4 \mathrm{mcg} / \mathrm{kg}$ over $60 \mathrm{~s}$ simultaneously with propofol $2.5 \mathrm{mg} / \mathrm{kg}$ infused over $45 \mathrm{sec}^{14}$

Groups A and B received rocuronium $0.6 \mathrm{mg} / \mathrm{kg}$ i.v. and succinylcholine $1 \mathrm{mg} / \mathrm{kg}$ i.v. respectively, for tracheal intubation.

Tracheal intubation was attempted: a) in group A, when T4/T1 was 0 (or even when 4 contractions were detected but T4/T1 ratio couldn't be calculated), b) in group B, when $\% \mathrm{TW}$ (T1/T0) was 0 and c) in group C, $150 \mathrm{~s}$ after the beginning of induction.

In group $\mathrm{C}$, if intubation was impossible on third attempt, for ethical reasons, succinylcholine, $1 \mathrm{mg} /$ $\mathrm{kg}$ i.v., was given to facilitate it and the case was excluded from the study. ${ }^{14}$

Laryngoscopy and intubation were attempted by the same experienced anesthesiologist. All the patients were intubated with a 7.0 or $8.0 \mathrm{~mm}$ (for women and men respectively) Nerve Integrity Monitor (NIM) Electromyography (EMG) Endotracheal Tube (Medtronic), with two paired wires (less than $1 \mathrm{~mm}$ in diameter) incorporated into the wall of it. The endotracheal tube cuff was inflated slowly.

The anesthesiologist performing the intubation assessed the intubating conditions with the Copenhagen score $\left(\mathrm{ICS}=\right.$ Intubation Condition Score). ${ }^{9}{ }^{15}$ (Appendix 1) The anesthesiologist who attempted the intubation ,thereafter, completed a questionnaire regarding the procedure, which allowed subsequent calculation of the IDS score (Intubation Difficulty Scale Score, seven variables). ${ }^{12}$ (Appendix 2 )

Appendix1. ICS (Intubation Condition Score) variables

\begin{tabular}{|l|l|l|l|}
\hline Laryngoscopy & Easy & Fair & Difficult \\
\hline Vocal cords position & Abducted & Moving & Closing \\
\hline Vocal cords movement & None & Slight & Closing \\
\hline Limb movement & None & Diaphragmatic movement & Vigorous \\
\hline Coughing & None & Good & Severe coughing \\
\hline
\end{tabular}

Quality of intubation can be excellent, good or poor.

Excellent: All scores are Excellent

Good: All scores are excellent or good

Poor: Any score is poor

Appendix2. IDS (Intubation Difficulty Scale) variables

\begin{tabular}{|l|l|}
\hline$N_{1}$ & Number of intubation attempts* $>1$ \\
\hline$N_{2}$ & The number of operators $>1$ \\
\hline$N_{3}$ & The number of alternative intubation techniques used \\
\hline$N_{4}$ & Glottic exposure [Cormack and Lehane grade minus 1] \\
\hline$N_{5}$ & Lifting force required during laryngeal pressure [0=normal; $1=$ increased] \\
\hline$N_{6}$ & Necessity for external laryngeal pressure [0=not applied; $1=$ applied] \\
\hline$N_{7}$ & Position of the vocal cords at intubation [0= abduction/not visualized; $1=$ adduction] \\
\hline
\end{tabular}

The IDS score is the sum of the aforementioned seven variables:

*An attempt is defined as one advancement of the tube in the direction of the glottis during direct laryngoscopy.

Ideal intubation conditions yield as IDS of 0 while progressively more difficult tracheal intubations result in higher scores.

The tube was connected with an Electromyographic (EMG) monitor (Medronic, NIM - Response 3.0 System).

Our routine was to stimulate the recurrent laryngeal nerves before and after thyroid gland's dissection. Particularly, we used the stimulator continuously before, as well as during the surgical exposure of the nerve into the tracheoesophageal groove. At the closure of the case, the final test of RLNs was performed after removal of the surgical specimens and ensuring complete hemostasis of the surgical field. ${ }^{6}$ 
Anesthesia was maintained with remifentanil $0.05-0.25 \mathrm{mcg} / \mathrm{kg} / \mathrm{min}$, depending on patient's response and, approximately, $2 \%$ sevoflurane, so that MAC was, at least, 1 and BIS $<60$ (usually $40-$ 60). Just after the intubation of the trachea, $40 \mathrm{mgr}$ of parecoxib and $1 \mathrm{mg} / \mathrm{kg}$ of pethidine where given i.v. and i.m. respectively. Before the end of the operation, $1 \mathrm{~g}$ of paracetamol was administered i.v. Hypotension (reduction of MAP > 25\% from baseline, for $60 \mathrm{sec}$ ), was treated with etilefrine 1-2 $\mathrm{mg}$ i.v. and bradycardia, (HR<50 bpm, for $60 \mathrm{sec}$ ), was treated with atropine $0.01 \mathrm{mg} / \mathrm{kg}$ i.v.

In group A, after neuromuscular blockade (NMB) was established by rocuronium, TOF/15 sec or PTC (Post Tetanic Count) stimulation/2 min was delivered (PTC stimulation was taking place when there was no response to TOF, because of a deep NMB). 15 min after the muscle relaxant was administered, or, when 2 responses were detected with PTC stimulation (no matter which one came first), $2 \mathrm{mg} / \mathrm{kg}$ sugammadex were administered i.v. Responses to TOF stimulation were recorded till $\mathrm{T} 4 / \mathrm{T} 1=0.9-1$ (NMB fully reversed). ${ }^{10,11}$

In cases where 3 min after administration of rocuronium, 4 responses were detected with TOF, but, T4/T1 ratio couldn't be calculated, the trachea was intubated and just after the intubation was completed, sugammadex, $2 \mathrm{mg} / \mathrm{kg}$, was given i.v. ${ }^{10}$

In group $\mathrm{A}$, our target was to reverse the $\mathrm{NMB}$ established by rocuronium, using low doses of sugammadex, as soon as possible, after the intubation of the trachea. This way, we could, detect which was the minimum time interval, after rocuronium administration, that IONM could be used and evaluated accurately (as the patient was totally free from muscle relaxation).

In group B, after NMB by succinylcholine was established, single twitch height was continuously recorded, until full regression of the blockade to $90-100 \%$ of the control value. ${ }^{13}$ In every group were recorded : 1) SAP, DAP, MAP, HR, BIS,SpO2, before and after laryngoscopy, 2 ) every single parameter of ICS and IDS, 3) the possibility of having a reliable IONM, 4) possible occurrence of intraoperative cough or movement, 5) the total dose of vasopressor agent administered and 6) the side effects noticed over the next 24 hours as nausea, vomiting, dry mouth, myalgia, abnormal taste, abnormal smell, distended abdomen, cough, hoarseness, laryngeal pain.

In groups A and B was also recorded: 7) the time needed for the patient to be totally free from muscle relaxation.

\section{STATISTICAL ANALYSIS}

Quantitative variables were expressed as mean values (SD) or as median (interquantile range), while qualitative variables were expressed as absolute and relative frequencies. For the comparison of proportions chi-square and Fisher's exact tests were used. Analysis of variance (ANOVA) was used for the comparison of means of continuous variables. Kruskall - Wallis test was used for the comparison of not normal continuous variables between the three study groups. Bonferroni correction was used in order to control for type I error, in case of multiple testing. Paired Student's t-tests were used for comparisons between before and after laryngoscopy. All reported p-values are two-tailed. Statistical significance was set at $\mathrm{p}<0.05$ and analyses were conducted using SPSS statistical software (version 19.0)

\section{Results}

The sample consisted of 75 patients, divided in 3 groups A, B, C.

Three (3) patients scheduled not to receive muscle relaxant -group C-, were finally excluded from the trial, because they received succinylcholine, as it was impossible to intubate them, even on the third attempt, without relaxation.

Finally, groups A and B consisted of 25 patients each (34, 7\% each), whereas group C consisted of 22 patients $(30,6 \%)$.

There were no significant differences among the three study groups as far as age, sex and smoking habits. Mean duration of surgery was similar among all study groups. (Table I)

The proportion of subjects with good/excellent ICS was $84.0 \%$ in group A, $68.0 \%$ in group B and $31.8 \%$ in group C. The aforementioned proportion for good/excellent ICS was significantly greater in groups $\mathrm{A}$ and $\mathrm{B}$ compared to group $\mathrm{C}(\mathrm{p}<0.001$ and $\mathrm{p}=0.013$, respectively). No significant difference was found in the correspondence proportion between groups $A$ and $B(p>0.05)$. (Figure 1)

Median IDS was 0 for group A (IQR=0-2), 1 for group B (IQR=0-2) and 1 for group C (IQR=0-3). 
IDS did not differ significantly among the three study groups $(\mathrm{p}=0.279)$.

In groups A and B, mean SAP, DAP, MAP and HR increased significantly after laryngoscopy.

In group $\mathrm{C}$, only MAP increased significantly, after laryngoscopy. (Table II)

$\mathrm{SpO} 2$ and BIS mean values did not change significantly after laryngoscopy in all study groups. (Table II)

The quality of recurrent laryngeal nerves monitoring, as well as percentages of intraoperative cough occurrence were similar in all groups. In contrast percentages of intraoperative movement occurrence as well as percentages of patients who received atropine differed significantly among groups. More specifically, after Bonferroni correction, it was found that the percentage of intraoperative movement occurrence was significantly higher in group $\mathrm{C}$, compared to group $\mathrm{B}(\mathrm{p}=0.014)$ as well as that patients in group A received atropine in a significantly higher percentage, than those in group $\mathrm{C}$ $(\mathrm{p}=0.014)$. (Table III)

The average time for NMB reversal with sugammadex $2 \mathrm{mg} / \mathrm{kg}$ after rocuronium administration, in group A, was significantly higher, compared to the average time for neuromuscular junction recovery, after succinylcholine administration, in group B.(Table IV )

The time after sugammadex $2 \mathrm{mg} / \mathrm{kg}$ administration, till reversal of NMB provided by $0.6 \mathrm{mg} / \mathrm{kg}$ rocuronium, was $4,6 \pm 3$ min.

There were no significant differences, regarding adverse events, among all study groups (Table V)

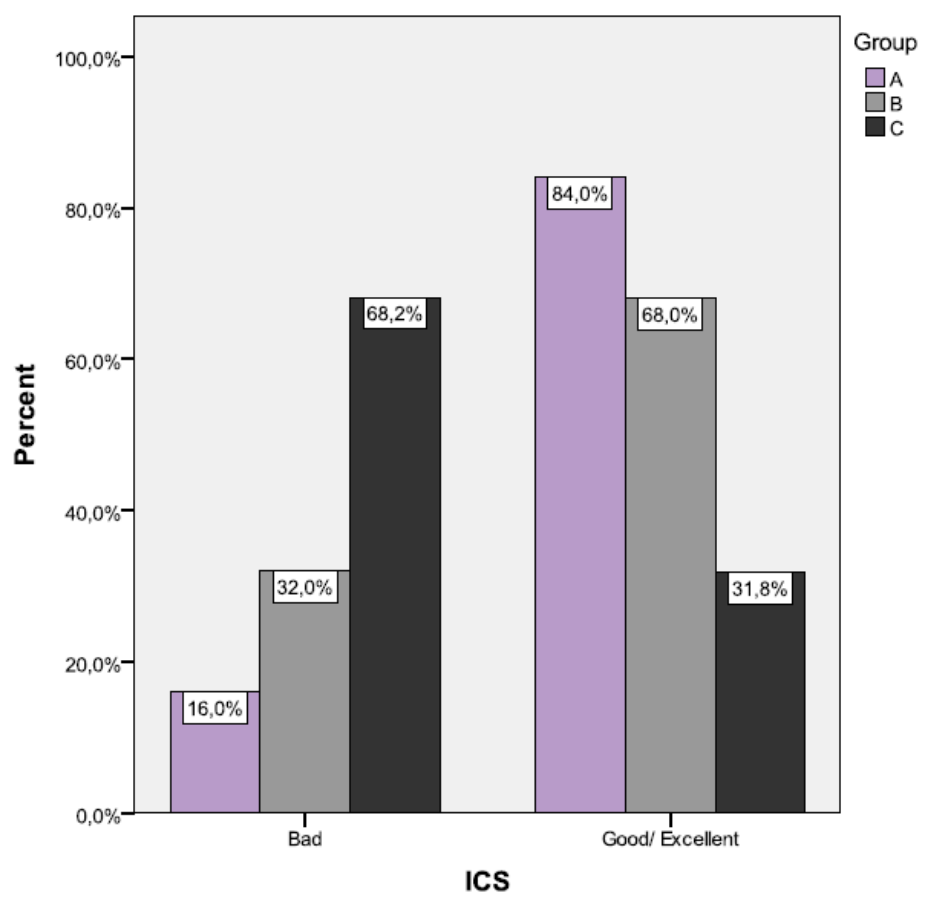

Figure1. ICS (Intubation Condition Score) of the three study groups

TableI. Demographics, Clinical Characteristics and Duration (Min) of Surgery

\begin{tabular}{|l|l|l|l|l|}
\hline & \multicolumn{3}{|c|}{ Group } & \\
\hline & $\mathbf{A}$ & $\mathbf{B}$ & $\mathbf{C}$ & \\
\cline { 5 - 6 } & $\mathbf{N}=\mathbf{2 5 0})$ & $\mathbf{N}=\mathbf{2 5})$ & $\mathbf{2 2})$ & \\
\hline & $\mathbf{N}(\%)$ & $\mathbf{N}(\mathbf{\%})$ & $\mathbf{N}(\%)$ & $\mathbf{P}$ \\
\hline Sex & & & & \\
\hline Men & $6(24.0)$ & $6(24.0)$ & $8(36.4)$ & $0.559^{*}$ \\
\hline Women & $19(76.0)$ & $19(76.0)$ & $14(63.6)$ & \\
\hline Age, mean (SD) & $51.6(17.0)$ & $51.0(15.7)$ & $49.3(13.8)$ & $0.866^{*}$ \\
\hline Smoking & & & & \\
\hline No & $18(72.0)$ & $12(48.0)$ & $10(45.5)$ & $0.121^{*}$ \\
\hline Yes & $7(28.0)$ & $13(52.0)$ & $12(54.5)$ & \\
\hline Duration of surgery, mean (SD) & $\begin{array}{l}134.1 \\
(41.3)\end{array}$ & $140.5(42.0)$ & $135.9(53.4)$ & $0.878^{*}$ \\
\hline
\end{tabular}

*Pearson's chi square test; +ANOVA; \#Kruskal-Wallis test 
Intraoperative Rocuronium Reversion by Low Doses of Sugammadex, in Thyroid Surgery, with Monitoring of the Recurrent Laryngeal Nerves

TableII. SAP (mm Hg), DAP (mmHg), MAP (mmHg), HR (bpm), SpO2 (\%) kal BIS before and after laryngoscopy

\begin{tabular}{|l|l|l|l|l|l|}
\hline & & $\begin{array}{l}\text { Before } \\
\text { laryngoscopy }\end{array}$ & $\begin{array}{l}\text { After } \\
\text { laryngoscopy }\end{array}$ & Change & \\
\hline & Group & Mean (SD) & Mean (SD) & Mean (SD) & P* \\
\hline SAP & A & $100.8(18.6)$ & $118.0(26.3)$ & $17.2(30.5)$ & 0.009 \\
\hline & B & $101.5(16.4)$ & $122.7(19.1)$ & $21.2(14.6)$ & $<0.001$ \\
\hline & C & $89.4(17.9)$ & $97.6(18.4)$ & $8.3(19.1)$ & 0.055 \\
\hline DAP & A & $59.1(10.7)$ & $78.3(19.8)$ & $19.2(21.6)$ & $<0.001$ \\
\hline & B & $60.7(10.0)$ & $74.2(14.8)$ & $13.5(15.4)$ & $<0.001$ \\
\hline & C & $53.9(13.5)$ & $60.0(13.9)$ & $6.1(14.8)$ & 0.066 \\
\hline & A & $73.8(13.6)$ & $93.9(22.6)$ & $20.1(26.4)$ & 0.001 \\
\hline & B & $73.6(11.3$ & $91.5(15.2)$ & $17.9(14.7)$ & $<0.001$ \\
\hline HR & C & $65.6(14.1)$ & $72.4(15.4)$ & $6.8(14.8)$ & 0.043 \\
\hline & A & $66.7(10.9)$ & $83.2(14.5)$ & $16.4(10.7)$ & $<0.001$ \\
\hline & B & $67.9(9.3)$ & $75.4(9.7)$ & $7.5(8.7)$ & $<0.001$ \\
\hline SpO2 & C & $68.8(16.4)$ & $71.0(13.4)$ & $2.3(11.7)$ & 0.372 \\
\hline & A & $99.2(1.0)$ & $99.1(1.0)$ & $0.0(0.8)$ & 0.814 \\
\hline & B & $99.4(0.8)$ & $99.0(0.9)$ & $-0.4(1.0)$ & 0.071 \\
\hline BIS & C & $99.0(1.1)$ & $99.3(0.6)$ & $0.3(1.1)$ & 0.266 \\
\hline & A & $33.5(9.6)$ & $32.8(10.7)$ & $-0.7(11.4)$ & 0.754 \\
\hline & B & $32.8(13.4)$ & $35.4(10.5)$ & $2.6(16.2)$ & 0.430 \\
\hline & C & $31.6(13.4)$ & $30.5(9.9)$ & $-1.1(12.9)$ & 0.695 \\
\hline
\end{tabular}

*paired t-test

TableIII. Quality of recurrent laryngeal nerves monitoring, intraoperative cough and movement occurrence, drugs and fluids intraoperatively administered

\begin{tabular}{|l|l|l|l|l|}
\hline & \multicolumn{2}{|l|}{ Group } & C & B \\
\hline & A & N (\%) & N (\%) & P \\
\hline Quality of laryngeal nerve monitoring & N (\%) & & & \\
\hline Poor & $1(4.0)$ & $0(0.0)$ & $0(0.0)$ & $1.000^{*}$ \\
\hline Good & $24(96.0)$ & $25(100.0)$ & $22(100.0)$ & \\
\hline Intraoperative cough & & & & \\
\hline No & $22(88.0)$ & $16(64.0)$ & $13(59.1)$ & $0.061^{*}$ \\
\hline Yes & $3(12.0)$ & $9(36.0)$ & $9(40.9)$ & \\
\hline Intraoperative movement & & & & \\
\hline No & $22(88.0)$ & $23(92.0)$ & $13(59.1)$ & $0.013^{*}$ \\
\hline Yes & $3(12.0)$ & $2(8.0)$ & $9(40.9)$ & \\
\hline Atropine use & & & & \\
\hline No & $19(76.0)$ & $24(96.0)$ & $22(100.0)$ & $0.015^{*}$ \\
\hline Yes & $6(24.0)$ & $1(4.0)$ & $0(0.0)$ & \\
\hline Total Etilefrine dose (mgr), median (IQR) & $0(0-1)$ & $0(0-1)$ & $0(0-1)$ & $0.626+$ \\
\hline & 1200 & 1200 & 1300 & \\
\hline Total Volume of fluids (ml), median (IQR) & $(1100-1500)$ & $(1200-1500)$ & $(1200-1600)$ & $0.461+$ \\
\hline Total remifentanil dose (mcgr), mean (SD) & $1088.8(487.1)$ & $1045.2(363.1)$ & $1099.5(294.2)$ & $0.879 \#$ \\
\hline
\end{tabular}

*Fisher's exact test; **Pearson's chi-square test; +Kruskal-Wallis test $; \neq$ ANOVA

TableIV. Time (Min) Needed After the NMBA Administration for the Remission of the Neuromuscular Blockade (Pharmaceutical or Automatic), in Groups A and B.

\begin{tabular}{|l|l|l|l|}
\hline & \multicolumn{2}{|l|}{$\begin{array}{l}\text { Mean time for neuromuscular junction recovery, after } \\
\text { NMBA administraiton }\end{array}$} & P Student's t-test \\
\hline Group & Mean Value & SD & \\
\hline A & 16,9 & 4,8 & 0,002 \\
\hline B & 11,7 & 6,4 & \\
\hline
\end{tabular}


Margarita Kontoudi et al.

TableV. Adverse events presented into the first postoperative day

\begin{tabular}{|l|l|l|l|l|}
\hline & \multicolumn{2}{|l|}{ Group } & \\
\hline & $\mathbf{A}$ & $\mathbf{B}$ & $\mathbf{C}$ & \\
\hline Nausea & $\mathbf{N}(\%)$ & $\mathbf{N}(\%)$ & $\mathbf{N}(\boldsymbol{\%})$ & $\mathbf{P}$ \\
\hline Vomiting & $\mathbf{2 ( 8 . 0 )}$ & $\mathbf{4 ( 1 6 . 0 )}$ & $\mathbf{1 ( 4 . 5 )}$ & $\mathbf{0 . 4 9 0}$ \\
\hline Dry mouth & $2(8.0)$ & $1(4.0)$ & $0(0.0)$ & $0.769^{*}$ \\
\hline Muscle pain & $14(56.4)$ & $17(68.0)$ & $17(77.3)$ & $0.299^{*}$ \\
\hline Abnormal smell & $0(0.0)$ & $0(0.0)$ & $0(0.0)$ & $-\neq$ \\
\hline Cough & $0(0.0)$ & $1(4.0)$ & $0(0.0)$ & $1.000^{*}$ \\
\hline Hoarseness & $2(8.0)$ & $2(8.0)$ & $0(0.0)$ & $0.539^{*}$ \\
\hline Laryngeal pain & $10(40.0)$ & $6(24.0)$ & $5(22.7)$ & $0.335^{*}$ \\
\hline
\end{tabular}

*Fisher's exact test; **Pearson's chi-square test; +Kruskal-Wallis test; $\neq$ not computed due to no distribution

\section{DisCUSSION}

The results of the present study indicate that rocuronium $0.6 \mathrm{mg} / \mathrm{kg}$ resembles succinylcholine in producing good to-excellent intubating conditions, in most of the cases.

In contrast, the third method of induction in anesthesia, in a statistical significant degree, didn't provide the good / excellent intubation conditions that the other two methods provided . ${ }^{14,15}$ There were not any statistical significant differences among the three study groups, in any other parameter evaluated in our study (except MAP fluctuations before - after laryngoscopy).

Succinylcholine is the most common drug suggested to be used in this short of cases where IONM is used, because it has a short duration of action. However, it is associated with a variety of adverse effects; from minor to very serious. ${ }^{15}$

Alternatively, it is referred that, low doses of rocuronium $(0.3 \mathrm{mg} / \mathrm{kg})$ can be used. Low-dose rocuronium $(0.3 \mathrm{mg} / \mathrm{kg})$ has favorable recovery profile on the laryngeal muscles, but, it does not provide good/ excellent intubating conditions. This policy was used in our Institution till recently. On the other side, rocuronium, in a dose of $0.6 \mathrm{mg} / \mathrm{kg}$, provides good/ excellent intubating conditions most of the times, but, it hasn't favorable recovery profile on the laryngeal muscles. ${ }^{2,7}$

Sugammadex, a novel and unique compound designed as an antagonist of rocuronium and other steroidal neuromuscular blockers, offers the opportunity to change anesthesia practice. Even deep levels of neuromuscular blockade, induced by rocuronium, can be promptly antagonized, intraoperatively, with appropriate low doses of sugammadex. In our studied objectives, we administered rocuronium $0.6 \mathrm{mg} / \mathrm{kg}$, and, the later $15 \mathrm{~min}$ after its administration, we reversed it, with $2 \mathrm{mg} / \mathrm{kg}$ sugammadex. ${ }^{10}$

By using low doses of sugammadex, we achieved muscle relaxation reversal, in 16, $9 \pm 4.8 \mathrm{~min}$, after rocuronium administration. This time is (significantly) higher than the time needed for the patient to get free from succinylcholine action (which is automatically withdrawn in $11,7 \pm 6.4 \mathrm{~min}$ ). However, sugammadex makes rocuronium (in a dose of $0.6 \mathrm{mg} / \mathrm{kg}$ ) a suitable muscle relaxant agent for induction in anesthesia for this specific operation in our Institution, where the first stimulation to RLNs is delivered around 30-45 min after the administration of the muscle relaxant agent. There were some limitations in this study: 1) the patients couldn't be randomly separated in the three study groups and the study couldn't be blind, 2) the patients of group B were selected - for ethical reasons -, in order to minimize the possibility of adverse effects.

\section{Conclusions}

In conclusion, we recommend the use of rocuronium $0.6 \mathrm{mg} / \mathrm{kg}$ instead of succinylcholine for the provision of muscle relaxation for induction of anesthesia in thyroid surgery. The administration of low-dose sugammadex $(2 \mathrm{mg} / \mathrm{kg}$ ) for reversal of rocuronium makes it also suitable for operations where the use of IONM of RLNs is needed.

We strongly suggest, as well, the administration of rocuronium - reversed as soon as possible by low dose of sugammadex - over the avoidance of muscle relaxants in order to achieve better intubation conditions. 


\section{REFERENCES}

[1] Manuel C Duran Poveda, Gialorenzo Dionigi, Antonio Sitges-Serra, Marcin Barczynski, Peter Angelos, Henning Dralle, Eimear Phelan, Gregory Randolph. Intraoperative monitoring of the RLN during thyroidectomy: A standardizes approach (Part 1). World journal of Endocrine Surgery, September - December 2011; 3 (3): 144-150.

[2] Ahmed Deniwar, Parisha Bhatia and Emad Kandil, Electrophysiological neuromonitoring of the laryngeal nerves in thyroid and parathyroid surgery: A review. World J Exp Med. 2015 May 20; 5(2): 120-123.

[3] Calo, P.G., et al., Intraoperative recurrent laryngeal nerve monitoring in thyroid surgery: is it really useful? Clin Ter, 2013. 164(3): p. e193-8.

[4] Pietro Giorgio Calò, Giuseppe Pisano, Fabio Medas, Maria Rita Pittau, Luca Gordini, Roberto Demontis and Angelo Nicolosi. Identification alone versus intraoperative neuromonitoring of the recurrent laryngeal nerve during thyroid surgery: experience of 2034 consecutive patients. Journal of Otolaryngology - Head and Neck Surgery 2014, 43:16.

[5] Gregory W. Randolph, MD; Henning Dralle, MD, with the International Intraoperative Monitoring Study Group*: Hisham Abdullah, MD; Marcin Barczynski, MD; Rocco Bellantone, MD; Michael Brauckhoff, MD; Bruno Carnaille, MD; Sergii Cherenko, MD; Fen-Yu Chiang, MD; Gianlorenzo Dionigi, MD, FACS; Camille Finck, MD; Dana Hartl, MD; Dipti Kamani, MD; Kerstin Lorenz, MD; Paolo Miccolli, MD; Radu Mihai,MD, PhD, FRCS; AkiraMiyauchi, MD, PhD; Lisa Orloff, MD, FACS; Nancy Perrier, MD, FACS; Manuel Duran Poveda, MD; Anatoly Romanchishen, MD; Jonathan Serpell, MD, FRACS, FACS; Antonio Sitges-Serra, MD; Tod Sloan, MD, MBA, PhD; Sam Van Slycke, MD; Samuel Snyder, MD, FACS; Hiroshi Takami, MD; Erivelto Volpi, MD; Gayle Woodson, MD. Electrophysiologic Recurrent Laryngeal Nerve Monitoring During Thyroid and Parathyroid Surgery: International Standards Guideline Statement. Laryngoscope, 121:S1-S16, 2011.

[6] Manuel C Duran Poveda, Gialorenzo Dionigi, Antonio Sitges-Serra, Marcin Barczynski, Peter Angelos, Henning Dralle, Eimear Phelan, Gregory Randolph. Intraoperative monitoring of the RLN during thyroidectomy: A standardizes approach (Part 2). World journal of Endocrine Surgery, January - April 2012; 4 (1):33-40.

[7] Lu, I.C., et al., A comparison between succinylcholine and rocuronium on the recovery profile of the laryngeal muscles during intraoperative neuromonitoring of the recurrent laryngeal nerve: a prospective porcine model. Kaohsiung J Med Sci, 2013. 29(9): p. 484-7.

[8] Ramkumar Venkateswaran, Souvik Chaudhuri, and K. M. Deepak. Comparison of intubating conditions following administration of low-dose rocuronium or succinylcholine in adults: A randomized double blind study. Anesth Essays Res. 2012 Jan-Jun; 6(1): 62-69.

[9] Combes X, Andriamifidy L, Dufresne E Comparison of two induction regimens using or not using muscle relaxant: impact on postoperative upper airway discomfort. Br J Anaesth vol. 99, 276-281, 2007.

[10] Philippe Duvaldestin, MD, Karel Kuizenga, MD, PhD, Vera Saldien, MD, Casper Claudius, MD, $\mathrm{PhD}$, Frederique Servin, MD, Jan Klein, MD, PhD, Bertrand Debaene, MD, Marten Heeringa, PhD. A Randomized, Dose - Response Study of Sugammadex Given for the Reversal of Deep Rocuronium - or Vecuronium - Induced Neuromuscular Blockade Under Sevoflurane Anesthesia. Anesth Analg 2010; 110:74-82.

[11] Mohamed Naguib, MB, BCh, MSc, FFARCSI, MD. Sugammadex: Another Milestone in Clinical Neuromuscular Pharmacology. Anesthesia \& Analgesia Vol. 104, No. 3, March 2007.

[12] J. McElwain1 and J. G. Laffey. Comparison of the C-MACw, Airtraqw, and Macintosh laryngoscopes in patients undergoing tracheal intubation with cervical spine immobilization British Journal of Anaesthesia 107 (2): 258-64 (2011). 
[13] Simon Hughes, Richard Griffiths. Anaesthesia Monitoring Techniques. Anaesthesia and Intensive Care Medicine, the Medicine Publishing Company Ltd, 2002.

[14] Thomas Mencke, Refa Maria Jacobs, Susann Machmueller, Martin Sauer, Christine Heidecke, Anja Kallert,Hans Wilhelm Pau, Gabriele Noeldge- Schomburg and Attila Ovari. Intubating conditions and side effects of propofol, remifentanil and sevoflurane compared with propofol, remifentanil and rocuronium: a randomised, prospective, clinical trial. BMC Anesthesiology 2014 ,

[15] Raghavendra TR, Yoganarasimha N, Radha M, Madhu R. A clinical study to compare the ease of intubation with combination of sevoflurane and propofol with propofol alone. Innovative Journal of Medical and Health Science 3: 3 May - June. (2013) 143 - 148. 